\title{
Seroprevalence of hepatitis E among restaurant food handlers in Ibadan, Nigeria
}

\author{
ADEOLA FOWOTADE ${ }^{*}$, OLUSEYI AKANDE ${ }^{2}$, ADEBIMPE T. GBAJA $^{1}$, VICTORIA O. OGUNLEYE $^{1}$, AYOMIDE AJAYI $^{1}$ \\ and ADEREMI O. KEHINDE ${ }^{1}$ \\ ${ }^{1}$ Department of Medical Microbiology and Parasitology, College of Medicine, University of Ibadan, Nigeria \\ ${ }^{2}$ Department of Medicine, College of Medicine, University of Ibadan, Nigeria
}

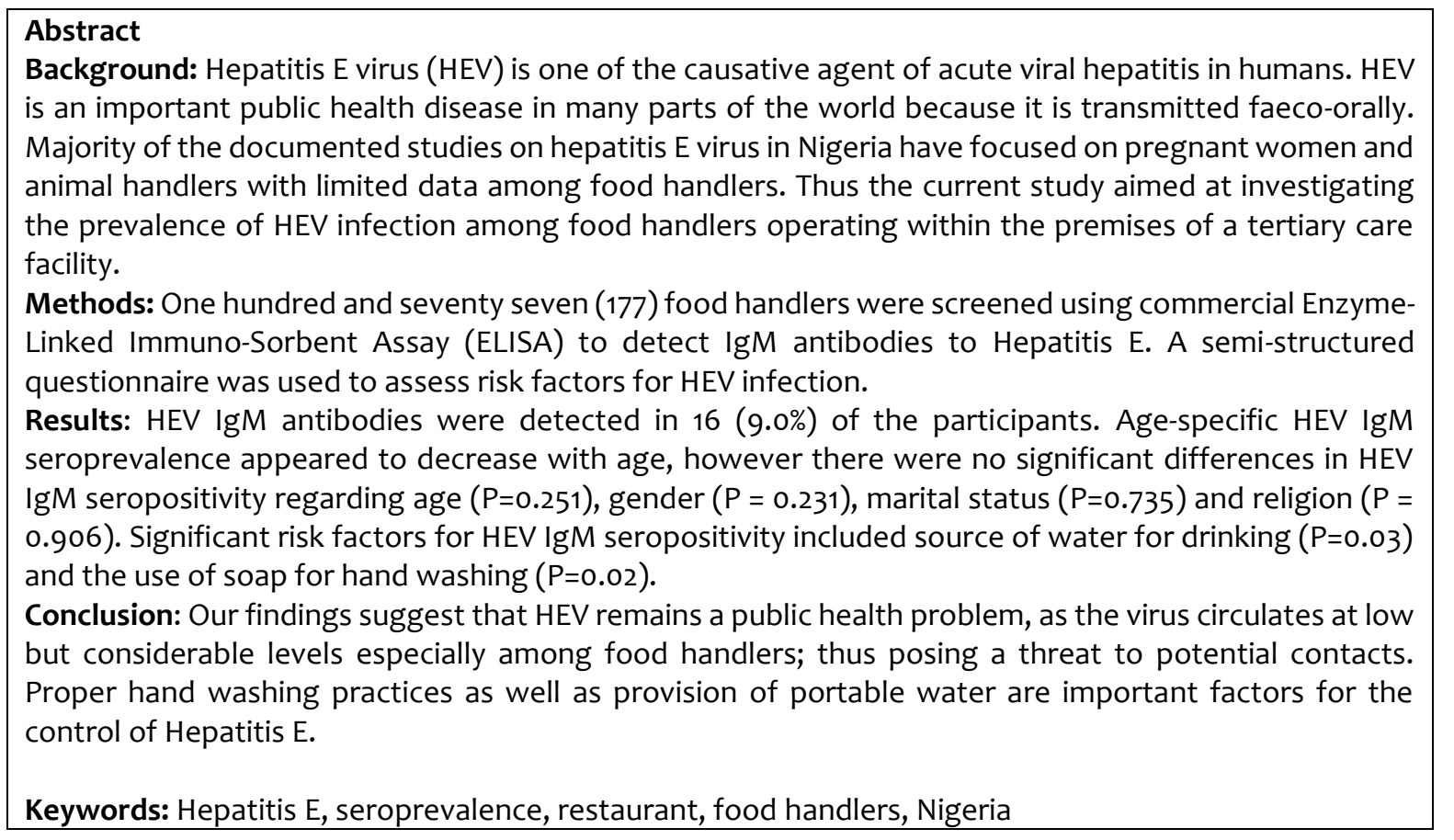

\section{Introduction}

Hepatitis E virus (HEV) infections is a common cause of enterically transmitted hepatitis and it occurs mainly in countries with poor hygienic conditions (Boccia et al., 2006; Panda et al., 2007). The causative agent of Hepatitis E infection is Hepatitis E virus, a non-enveloped single-stranded, positive sense RNA virus. It is associated with sporadic cases occurring in clusters as well as major outbreaks of acute hepatitis, particularly in developing countries (Aggarwal et al., 2013). HEV is harboured by domestic pigs, deer and some other domestic animals or their products. Zoonotic transmission is well recognized with pigs serving as the reservoir for human infections (Mang, 2003; Purcell \& Emerson, 2003). More recent studies have shown that beside the already known faeco-oral transmission of HEV, other routes of transmission such as the parenteral route, personto-person and perinatal mode of transmission are also possible (Mateos-Lindmann et al., Bouamura et al., 2013; Lanini et al., 2015). Globally, HEV infections have been found to be the most or second most common cause of acute viral Hepatitis among adults resident in Africa, Asia and Middle East (Yusuf et al.,2015)). In Africa, HEV infection is found to cause infections among human population in 28 out of 56 African countries (Jong-Hoon et al., 2014). Since 1979, HEV outbreaks have been reported on a yearly basis in various parts of Africa causing a reported 35,300 cases with 650 deaths (Colson et al., 2010).

HEV contamination of meat and meat products constitutes a threat to food safety as it puts the consumers at risk of foodborne hepatitis E (Tei et al. 2003; Yazaki et al., 2003; Colson et al.,

\footnotetext{
* Correspondence E-mail: temilabike@gmail.com
} 
2010). HEV infection among immunosuppressed persons results in outbreak of food borne illnesses, often with disastrous consequences. Although HEV infection is associated with rapid viral clearance in some instances, it may also be associated with progression to liver cirrhosis and persistent viral shedding, especially among the immunosuppressed patients (Haagsoma et al., 2008; Dalton et al., 2009). More recently, there has been growing public interest in food safety. Street food and food from restaurants with low level of hygiene may constitute a public health hazard (Allan, 2002). A previous study has observed a low level of personal hygiene among food handlers largely due to poor knowledge and attitudes towards food hygiene practices (Ezenkwo et al., 2017). The restaurants considered in our study have a large clientele base, ranging from the hospital staff to the patients and their relatives.

To the best of our knowledge, majority of the HEV studies in Nigeria were conducted among animal handlers and pregnant women (Bertin et al., 2009; Junaid et al., 2014; Ezenwoko et al., 2017). There is paucity of information on the prevalence of hepatitis $E$ virus infection among food handlers who could serve as important reservoir and source of transmission of the virus to their clientele and by extension to the populace. The aim of the current study was to determine the burden of HEV infection among food handlers and to assess the risk factors for infection.

\section{Materials and Methods}

\section{Study area}

This cross-sectional study was carried out in March and April, 2018 at the University College Hospital $(\mathrm{UCH})$, Ibadan. UCH, Ibadan is the leading Nigerian tertiary health care facility, located in Ibadan, Oyo state, Nigeria. According to the 2006 census, Ibadan has a population of 2,559,833, it is one of the largest city in West Africa, divided into urban and rural areas, measuring $3,080 \mathrm{~km}^{2}$ and $6,800 \mathrm{~km}^{2}$, respectively. The UCH, Ibadan provides services to patients from the parent state and other neighbouring states, it has a total bed capacity of 800 .

\section{Study population}

All the 12 restaurants within the premises of the University College Hospital, Ibadan were recruited into the study. The food handlers were selected by stratified sampling and the number of restaurants visited were 12 in number. Consenting food handlers were assigned numbers and successive even numbers who met the inclusion criteria were recruited. All the food handlers aged less than 18 years or those who had been in employment for a period of less than 3 months were excluded from the study.

\section{Data collection}

Five-mL of blood were obtained from each participant by venipuncture using aseptic technique. A semi-structured interviewer administered questionnaire was used to obtain demographic data and information on personal and environmental hygiene.

\section{Sample processing}

Samples were centrifuged and sera was separated immediately and stored at $-20^{\circ} \mathrm{C}$. All samples were tested for the presence of anti-HEV IgM antibody using enzyme-linked immunosorbent assay (ELISA) kits according to the protocols provided by DIAPRO, Milan, Italy. The assays were performed according to the instructions of the manufacturer. Briefly, the kits contained microwells which were coated with HEV-specific synthetic antigens derived from oral reading frame 2 and 3 (ORF2 and ORF3) regions of the HEV genome from genotypes 1 and $2 \mathrm{HEV}$ strains. The solid phase was treated with the diluted sample to capture the anti HEV IgM, if present, by antigens on the wells. After washing out all other components of the sample, in the second incubation bound anti HEV IgM antibodies are detected by the addition of polyclonal specific IgM antibodies. The presence of anti-HEV IgM antibody was considered as the evidence of recent infection with HEV. 


\section{Data analysis}

All collected data were analyzed using the Statistical Package for Social Sciences (SPSS) version 20.0 statistical software (SPSS, Inc., Chicago, IL, USA). Pearson Chi-square test was used to establish association between serological results and different risk factors considered in the study. This was to determine whether a variable was associated with HEV infection. All $P$ values were based on a two-sided test of statistical significance. Significance was accepted at the level of $P<$ 0.05 .

\section{Ethical considerations}

This study was approved by Joint Ethical Committee of the University of Ibadan and the University College Hospital, Ibadan. The purpose and procedure of the surveys were explained to all participants, and informed consent was obtained from each food handler before collecting the samples. The confidentiality of each participant was also protected by using code instead of names.

\section{Results}

\section{Sociodemographic characteristics}

One hundred and seventy seven blood samples collected from food handlers in Ibadan, Oyo State were tested for HEV anti-IgM. Eligible food handlers were recruited from twelve different restaurants located on the premises of the University College Hospital, Ibadan. Majority were females, 149 (85.1\%) giving a female: male ratio of 5.3:1. The age range of the participants ranged from 22 to 54 years with a mean age of $33.40 \pm 8.84$ years. Majority, $62(37.1 \%)$ were within the age group, 20-30 years while minority, 15 (15\%) fell within the age group >50 years. Most of the participants, $106(59.9 \%)$ were married while only $1(0.6 \%)$ of the participants was divorced. Majority, $74(41.8 \%)$ had at least secondary level of education while minority, $12(6.8 \%)$ had no formal education. Majority of the participants, 118 (66.7\%) practised Christianity religion while the others were Muslims, 59 (34.3\%).

\section{HEV IgM Seropositivity}

Among the 177 participants, 16 (9.0\%) were seropositive for HEV IgM antibodies. Half (50\%) of the HEV IgM seropositive participants were within the age group, 20 to 30 years and, predominantly (75.0\%) females. A total of 6 out of $16(37.5 \%)$ of the HEV IgM seropositive participants had tertiary level of education and $11(68.75 \%)$ of the seropositive participants were married. A total of 14 out of $16(87.5 \%)$ of the participants were from the Yoruba ethnic group. However, there was no statistically significant association between HEV IgM seropositivity and the sociodemographic parameters; age $(P=0.251)$, gender $(P=0.231)$, level of education $(P=0.663)$, marital status $(P=0.735)$ and ethnicity $(\mathrm{P}=0.072)$.

\section{Distribution of Hepatitis E IgM seropositivity and food handlers' risk behaviour}

All participants claimed to wash their hands after using the toilet. The current study found that the use of soap for hand washing $(P=0.02)$ as well as the source of water for drinking $(P=0.03)$ were statistically significant factors for HEV IgM seropositivity. Majority (94.3\%) wash their hands with soap and water as against the few (5.7\%), who wash their hands with only water. Other risk factors found not to be significant include; frequency of hand washing $(P=0.66)$ and use of cutlery for eating $(\mathrm{P}=0.82)$. Additionally, risk behaviour that could put customers at risk of exposure to HEV infection were found not to be statistically significant. Majority, $153(86.9 \%)$ wash their hands before serving food and a total of 115 (75.2\%) wash their apron on a daily basis. Majority, 119 (69.6\%) of the participants do not wear gloves while serving food (Table 1). 
Table 1: Association between personal hygiene and HEV seropositivity among food handlers $(\mathrm{n}=177)$

\begin{tabular}{|c|c|c|c|c|}
\hline Variables & Response & Frequency & Percentage & P-value \\
\hline \multirow{2}{*}{$\begin{array}{l}\text { Do you always wash your hands after } \\
\text { using the toilet? }\end{array}$} & Yes & 177 & 100 & NA \\
\hline & No & 0 & 0 & \\
\hline \multirow[t]{2}{*}{ What do you wash your hands with? } & Water only & 12 & 6.8 & 0.02 \\
\hline & Water+soap & 165 & 93.2 & \\
\hline \multirow{8}{*}{$\begin{array}{l}\text { Where do you wash your hands after } \\
\text { leaving the toilet? } \\
\text { How often do you wash your hands? }\end{array}$} & Toilet & 165 & 93.2 & 0.92 \\
\hline & Kitchen & 12 & 6.8 & \\
\hline & After using the toilet & 6 & 3.4 & 0.66 \\
\hline & Before eating only & 3 & 1.7 & \\
\hline & After eating only & 2 & 1.1 & \\
\hline & Before and after eating & 8 & 4.5 & \\
\hline & $\begin{array}{l}\text { When the hands appear } \\
\text { soiled }\end{array}$ & 156 & 88.1 & \\
\hline & Thrice daily & 2 & 1.2 & \\
\hline \multirow[t]{3}{*}{ What do you always eat with? } & Hand & 26 & 14.7 & 0.82 \\
\hline & Cutlery & 109 & 61.6 & \\
\hline & Both & 42 & 23.7 & \\
\hline \multirow{2}{*}{$\begin{array}{l}\text { Do you wash your hands before } \\
\text { serving food? }\end{array}$} & Yes & 153 & 87 & 0.40 \\
\hline & No & 24 & 13 & \\
\hline \multirow[t]{4}{*}{ When last did you deworm yourself? } & Six months ago & 40 & 22.6 & 0.17 \\
\hline & Three months ago & 32 & 18.1 & \\
\hline & Can't remember & 99 & 55.9 & \\
\hline & Never done so & 6 & 3.4 & \\
\hline \multirow[t]{5}{*}{ How often do you wash your apron? } & Everyday & 115 & 65.1 & 0.86 \\
\hline & Every other day & 15 & 8.4 & \\
\hline & Once a week & 19 & 10.7 & \\
\hline & Twice a week & 25 & 14.1 & \\
\hline & Thrice a week & 3 & 1.7 & \\
\hline \multirow[t]{2}{*}{ Do you wear gloves to serve food? } & Yes & 58 & 32.8 & 0.80 \\
\hline & No & 119 & 67.2 & \\
\hline \multirow[t]{5}{*}{ Source of drinking water } & Surface water & 20 & 11.3 & \\
\hline & Underground & 5 & 2.8 & \\
\hline & Borehole & 97 & 54.8 & 0.33 \\
\hline & Pipe borne & 11 & 6.2 & \\
\hline & Sachet water & 44 & 24.9 & \\
\hline
\end{tabular}

Distribution of Hepatitis E IgM seropositivity among food handlers and level of environmental hygiene

Majority, 87 (49.2\%) of the food handlers use bore-hole water while a few, $2(1.1 \%)$ use either rain water or well water for cooking. Majority, 137 (77.4\%) did not own/rear animals (poultry, goat, sheep, dog, cat and cow) in their home. Of the $22.6 \%$ that keep domestic animals, $59.4 \%$ kept poultry, followed by goats (18.8\%) and dogs (12.5\%). Majority, $48(27.3 \%)$ of the respondents lived in self-contained bungalows and a total of $104(60.8 \%)$ of the food handlers reported having rodents in their homes. In most instances, 154 (87\%), waste generated from the restaurants were being disposed of through refuse collectors while a minority, 8 (4.5\%) practiced open dumping. None of the environmental factors were statistically significant for HEV IgM seropositivity (Table 2). 
Table 2: Association between environmental hygiene and HEV IgM seropositivity among food handlers $(n=177)$

\begin{tabular}{|c|c|c|c|c|}
\hline Variables & Response & Frequency & Percentage & P-value \\
\hline \multirow{4}{*}{$\begin{array}{l}\text { What is the source of water that is } \\
\text { used to cook? }\end{array}$} & Rain water & 2 & 1.1 & \\
\hline & Borehole water & 87 & 49.2 & 0.87 \\
\hline & Tap water & 86 & 48.6 & \\
\hline & Well water & 2 & 1.1 & \\
\hline \multirow{2}{*}{$\begin{array}{l}\text { Do you have refuse dumps near your } \\
\text { restaurant? }\end{array}$} & Yes & 147 & 84.5 & 0.71 \\
\hline & No & 30 & $15 \cdot 5$ & \\
\hline \multirow{2}{*}{$\begin{array}{l}\text { Do you own/ rear animals in your } \\
\text { home? }\end{array}$} & Yes & 40 & 22.6 & 0.14 \\
\hline & No & 137 & 77.4 & \\
\hline \multirow[t]{5}{*}{ If Yes, specify the animal } & Poultry & 19 & 47.5 & \\
\hline & Goat & 6 & 15.0 & \\
\hline & Dog & 4 & 10.0 & 0.36 \\
\hline & Cow & 1 & 2.5 & \\
\hline & Poultry and Goat & 10 & 25.0 & \\
\hline \multirow[t]{2}{*}{ Do you have rodents in your home? } & Yes & 104 & 58.8 & 0.63 \\
\hline & No & 73 & 41.2 & \\
\hline \multirow[t]{6}{*}{ Which kind of house do you live in? } & Boys quarters & 35 & 19.8 & \\
\hline & Self-contained & 48 & 27.1 & 0.52 \\
\hline & Flat & 51 & 28.8 & \\
\hline & Duplex & 5 & 2.8 & \\
\hline & Single room unit & 35 & 19.8 & \\
\hline & Storey building & 3 & 1.7 & \\
\hline \multirow[t]{4}{*}{ How do you dispose your refuse? } & Open dumping & 8 & 4.5 & \\
\hline & Incineration & 6 & 3.4 & 0.86 \\
\hline & Bagging & 9 & 5.1 & \\
\hline & Refuse collection & 154 & 87.0 & \\
\hline
\end{tabular}

\section{Discussion}

Hepatitis E Virus (HEV) infection is transmitted through the faeco-oral route hence the need to assess the potential threat to customers who patronise food handlers. In this study, we report HEV IgM seroprevalence of $9.0 \%$ among food handlers in Ibadan. Our finding is much higher than the $0.9 \%$ reported among different populations including apparently healthy individuals in Plateau state, Nigeria (Junaid et al., 2014) as well as the $1.7 \%$ reported among patients with Human immunodeficiency virus infection in Ibadan, Nigeria (Odaibo \& Olaleye, 2013). Higher prevalence rates of HEV IgM have been reported among varied population in other endemic regions of the world. A similar study among food handlers in Khartoum, Sudan reported a higher seroprevalence rate of $15.5 \%$, while another report from Japan reported a seroprevalence rate of $13 \%$ (Bandyyopadhyay, 1993; Yusuf et al., 2015). The observed variation in seroprevalence rates might be attributed to the variation in the populations studied, the difference in the test kits used and the sample size studied. Additionally, socioeconomic and cultural differences as well as varied levels of hygiene across the different geographic regions might be contributory. Age-specific HEV IgM seroprevalence appeared to decrease with age, and the highest prevalence was found among participants aged 20-30 years while none of the participants was positive among subjects of 41-50 years. This might be as a result of the fact that majority of the participants are within the age group 20-30 years. There was no significant difference between seropositivity and age distribution.

It is not surprising that majority of the participants in this study were females, as females often occupy predominant position in the food industry, especially in developing countries (Lues 
et al., 2006). This is also in keeping with reports from other parts of Nigeria (Monney et al., 2014; Nurudeen et al., 2014; Ezenwoko et al., 2017). In contrast to reports from Ilorin, Nigeria (56.9\%) and Sokoto, Nigeria (23.2\%), only few of the food handlers from our study had no formal education (Musa \& Akande, 2003; Ezenwoko et al., 2017) . This might be because of the high literacy level in the South-western part of Nigeria compared with the North central and North West regions where these other studies were carried out.

Although no statistically significant difference was observed with regard to gender, this study recorded proportionately higher HEV prevalence among females than males. This finding contrasts a number of studies on Hepatitis E (Buti et al., 2008; Gouroba et al., 2011). This variation might be due to the fact that majority of the participants were females. The married group ran a significantly higher risk of HEV IgM seropositivity than the unmarried, although the result was not significant. This is consistent with the finding of Junaid et al. (2014), who also documented a higher prevalence among married people than singles.

The significant risk behaviour associated with HEV IgM seropositivity were source of water for drinking and hand washing with soap. This is not surprising as previous studies have shown that contaminated water supplies are important sources of HEV outbreaks in humans (Guthman et al., 1996; Buti, et al., 2008). Previous reports from studies among food handlers had observed a good knowledge of hand washing with soap among most of the respondents although, only a few consistently translate the knowledge into the practice of hand washing with soap (Ezenwoko et al., 2017).

Although the current study reports a low seroprevalence of HEV IgM among food handlers in Ibadan, Nigeria, our findings nonetheless suggests the possible risk of HEV transmission to potential contacts in these restaurants. Hand hygiene with use of soap or water only as well as source of water for drinking are important determinants for HEV IgM seropositivity. Health education on improved personal and environmental hygiene is recommended as well as large scale community based studies to define the prevalence and risk behaviour for $\mathrm{HEV}$ infection in Nigeria.

\section{Competing Interest}

The authors declare that there are no conflicts of interest regarding the publication of this article.

\section{Acknowledgments}

The authors would like to acknowledge the staff nurses in the Infection control unit of Medical Microbiology Department, UCH, Ibadan as well as Miss Gladys Ikwue for their cooperation in sample collection.

\section{Authors' contribution}

$A F, A O K, A A$ and GAT designed the study. AF and $A O$ analysed the data. AF wrote the manuscript with contributions of $A O$ and OVO. All the authors read and approved the final version of the manuscript.

\section{References}

Aggarwal, R. (2013) Diagnosis of hepatitis E. Journal of Gastroenterology and Hepatolology 10:2433.

Allan, D.G. (2002) The "farm to plate" approach to food safety-everyone business. Canadian Journal of Infectious Diseases 13: 185-190.

Bertin, P.F.H.C., Rezende, M.A., Sigulem, D.M. \& Morais, T.B. (2009) Hurdles at work: Perceptions of hospital food handlers. Human Research Health Journal 7:63. 
Buti, M., Domínguez, A., P.,Plands, P., Jardí, R., Schaper, M., Espuñes, J., Cardeñosa, N., RodríguezFrías, F., Esteban, R., Plasència, A. \& Salleras, L. (2006). Community-based seroepidemiological survey of hepatitis $\mathrm{E}$ virus infection in Catalonia, Spain. Clinical Vaccine Immunology 13:1328-1332.

Boccia, D., Guthmann, J.P., Klovstad, H., Hamid, N., Tatay, M., Ciglenecki, I., Nizou, J.Y., Nicand, E., Guerin, P.J. (2006) High mortality associated with an outbreak of hepatitis E among displaced persons in Darfur, Sudan. Clinical Infectious Diseases 42:1679-1684.

Colson, P., Borentain, P, Queyriaux, B., Kaba, M., Moal, V. \& Gallian, P. (2010) Pig liver sausage as a source of hepatitis E virus transmission to humans. Journal of Infectious Diseases 202:825834.

Dalton, H.R., Bendall, R.P., Keane, F.E., Tedder, R.S. \& ljaz, S. (2009). Persistent carriage of hepatitis E virus in patients with HIV infection. New England Journal of Medicine 361:1025-1027.

Ezenwoko, A.Z., Awosan, K.J., Oche, M.O., Makusidi, M.A., Abubakar, B.G. \& Raji, I.A. (2017). Knowledge and Practices Related to food Hygiene among food Handlers in Sokoto, Nigeria. International Journal of Tropical Disease \& Health 26: 1-16.

Jong-Hoon, K., Kenrad, N., Ursula, P., Yogita K., Alain, L. \& Thomas, W (2014) A Systemic review of the Epidemiology of Hepatitis E Virus in Africa. British Medical Journal of Infectious Diseases 14:308.

Junaid, S.A., Agina, S.E. \& Abubakar, K.A. (2014) Epidemiology and associated risk factors of hepatitis E virus infection in Plateau State, Nigeria. Virology: Research and Treatment. 5:15-26.

Lanini, S., Garbuglia, A.R., Lapa, D., Puro, V., Navarra, A., Pergola, C., Ippolito, G. \& Capobianchi, M.R. (2015) Epidemiology of HEV in the Mediterranean basin: 10-year prevalence in Italy. British Medical Journal Open 5:e007110.

Lues, J.F.R., Rasephei, M.R., Venter. P. \& Theron, M.M. (2006) Assessing food safety and associated food handling practices in street food vending. International Journal of Environmental Health Research 16: 319-328.

Mateos-Lindemann, M.L., Diez-Aguilar, M., Galdamez, A.L., Galan, J.C., Moreno, A. \& Perez-Gracia, M.T. (2014) Patients infected with HIV are at high-risk for hepatitis E virus infection in Spain. Journal of Medical Virology 86:71-74.

Monney, I., Agyei, D., Ewoenam, B.S., Priscilla, C. \& Nyais, S. (2014) Food hygiene and safety practices among food street food vendors: an assessment of constitutional, institutional and legislative framework in Ghana. Food Public Health 4: 306- 315.

Musa, O.I. \& Akande, T.M. (2003) Food hygiene practices of food vendors in secondary schools in Ilorin. Nigerian Postgraduate Medical Journal 10: 192-196.

Nurudeen, A.A., Lawal,. A.O. \& Ajayi, S.A (2014) A survey of hygienic and sanitary practices of street vendors in the central state of Northern Nigeria. Journal of Public Health Epidemiology 6: 174-181.

Odaibo, G.N. \& Olaleye, D.O. (2013) Hepatitis E virus infection in HIV positive ART naive and experienced individuals in Nigeria. World Journal of AIDS 3: 216-220.

Panda, S., Thakral D. \& Rehman S. (2007) Hepatitis E virus. Review in Medical Virology, 17. 151-180.

Purcell, R. \& Emerson, S. (2008) Hepatitis E: An emerging awareness of an old disease. Journal of Hepatology. 48:494-503.

Tei, S., Kitajima, N., Takahashi, K. \& Mishiro, S. (2003) Zoonotic transmission of hepatitis E virus from deer to human beings. Lancet 362:371-373.

Yazaki, Y., Mizuo, H., Takahashi, M., Nishizawa, T., Sasaki, N. \& Gotanda, Y. (2003) Sporadic acute or fulminant hepatitis $E$ in Hokkaido, Japan, may be food-borne, as suggested by the presence of hepatitis E virus in pig liver as food. Journal of General Virology 84: 2351-2357.

Yusuf, S., Garbi, M. \& Saad, F (2015). Seroprevalence of Hepatitis E among food handlers in Central Khartoum, Sudan. International Journal of Multidisciplinary Research and Development 2 (11):351-354. 